\title{
PENGARUH JENIS MINYAK TERHADAP SIFAT FISIK SABUN MANDI CAIR
}

\section{The Effect Of Oil Types On Physical Properties Of Liquid Bath}

\section{Febrina Nugrahini $^{1 *}$ \\ Nining Sugihartini ${ }^{2}$ \\ Laela Hayu Nurani ${ }^{3}$}

*IMahasiswa Pascasarjana

Farmasi Universitas Ahmad

Dahlan, Yogyakarta

2 Fakultas Farmasi Universitas

Ahmad Dahlan, Yogyakarta

3 Fakultas Farmasi Universitas

Ahmad Dahlan, Yogyakarta

*email: febrinanug@gmail.com

\section{Kata Kunci:}

Sabun mandi cair

Jenis minyak

sifat fisik sabun

\section{Keywords:}

Liquid bath soap

oil type

physical properties of soap

\begin{abstract}
Abstrak
Latar belakang: Sabun diperoleh dari reaksi saponifikasi yang terjadi antara minyak dengan larutan alkali. Berbagai macam minyak yang digunakan dalam pembuatan sabun juga memberikan pengaruh terhadap kualitas sabun.
\end{abstract}

Tujuan: Tujuan dari penelitian ini adalah untuk mengetahui pengaruh jenis minyak terhadap sifat fisik sabun mandi cair.

Metode penelitian: Penelitian ini dibagi menjadi 3 kelompok, kelompok minyak kelapa (A), kelompok minyak VCO (B), dan kelompok minyak zaitun (C). Sabun mandi cair yang diperoleh dari setiap jenis minyak diuji berdasarkan ketentuan SNI melipuyi uji mutu sabun (uji karakteristik minyak, uji organoleptik, uji $\mathrm{pH}$, bobot jenis, angka lempeng total), uji viskositas, dan uji antioksidan.

Hasil penelitian: Sabun mandi cair ketiga jenis minyak mempunyai bentuk, warna dan bau yang sama. Sabun mandi cair kelapa, VCO dan zaitun secara berturut-turut memiliki nilai $\mathrm{pH} 6,64 ; 6,9 ; 6,52 .(\mathrm{p}=0,000)$ Bobot jenis I,05II; I,0427; I,0425. Viskositas 558cps; 686; 420. $(p=0,003)$ IC50 3547,36; 4523,46; 3542,02. $(p=0,035)$

Kesimpulan: Sabun mandi yang paling memenuhi persyaratan SNI adalah yang dibuat dengan minyak zaitun.

\begin{abstract}
Background: Soap is obtained from the saponification reaction that occurs between oil and alkaline solution. Various kinds of oils used in soap making also affect the quality of soap.

Objective: The purpose of this study is to determine the effect of oil type on the physical propeties of liquid bath soap.

Methods: This research was divided into 3 groups, coconut oil group (A), VCO oil group (B), and olive oil group (C). Liquid bath soap obtained from each type of oil is tested based on $\mathrm{SNI}$ provisions including a soap quality test (oil characteristics test, organoleptic test, $\mathrm{pH}$ test, specific gravity, total plate count), viscosity test, and antioxidant test.

Result: Liquid bath soap of the three types of oil has the same shape, color and odor. Coconut liquid soap, VCO and olives respectively have a pH value of 6.64; 6.9; 6.52. ( $P=$ $0,000)$ Specific weight I.05II; I.0427; I.0425. Viscosity 558cps; 686; 420. $(p=0.003)$ IC50 3547.36; 4523.46; 3542.02. $(p=0.035)$
\end{abstract}

Conclusion: Bath soaps that best meet SNI requirements are those made with olive oil.

(c)

() year The Authors. Published by Institute for Research and Community Services Universitas Muhammadiyah Palangkaraya. This is Open Access article under the CC-BY-SA License (http://creativecommons.org/licenses/by-sa/4.0/). DOI: https://doi.org//0.33084/jsm.vxix.xxx.

\section{PENDAHULUAN}

Sabun adalah garam logam alkali (biasanya garam natrium) dari asam-asam lemak. Tidak ada catatan yang pasti kapan sabun pertama kali dibuat dan mulai digunakan, namun bentuk sabun dari zaman ke zaman mengalami perubahan mulai dari sabun batang hingga sabun cair. Di era modern ini, masyarakat lebih menyukai bentuk sabun cair karena dirasa lebih praktis dan higienis. sabun dapat digunakan untuk mencegah penyakit, seperti mencegah penyakit kulit yang disebabkan oleh bakteri (Kasenda et al, 2016).

Dalam pembuatan sabun, salah satu bahan baku yang digunakan yaitu lemak atau minyak. Minyak yang dipilih dalam penelitian ini yaitu minyak kelapa, minyak VCO dan minyak zaitun. Minyak VCO merupakan minyak yang berasal dari daging buah kelapa segar (bukan 
kopra) dibuat tanpa proses kimiawi dan suhu tinggi (Oktari, 20I7). Minyak zaitun berasal dari buah zaitun yang digiling kemudian dilakukan proses pemerasan selama 45 menit, hingga minyak zaitun muncul ke permukaan dan terpisah dengan air dan ampasnya. (Tiffani et al, 20I5). Masing-masing jenis minyak mempunyai komposisi atau kandungan yang berbeda. Untuk itu penelitian ini dilakukan untuk mengetahui sifat fisik dari masing-masing jenis sabun cair yang dihasilkan dan mengetahui jenis minyak yang paling baik untuk bahan baku pembuatan sabun mandi cair.

\section{METODOLOGI}

Jenis penelitian yang dilakukan adalah penelitian eksperimental dengan membandingkan jenis minyak terhadap sifat fisik sabun mandi cair dengan evaluasi organoleptik, $\mathrm{pH}$, bobot jenis, angka lempeng total dan uji viskositas.

\section{Alat dan Bahan}

Alat yang digunakan dalam pembuatan sabun mandi cair yaitu timbangan analitik (Scout Pro), timbangan digital (Citizen ${ }^{\circledR}$ MB 200), beaker glass (Pyrex), gelas ukur (Pyrex), piknometer (Isolab), $\mathrm{pH}$ meter (Mediatech), vortex meter (Amtast), Rotavapor (Eyela ${ }^{\circledR}$ OSB-2100), tabung reaksi (Iwaki), magnetic stirrer (Amtast), pipet ukur (Iwaki), pipet volume (Iwaki), cawan petri (lwaki), erlenmeyer asah (lwaki), viskometer (Rheosys), masker dan sarung tangan.

Pada penelitian ini digunakan bahan-bahan kimia antara lain akuades, minyak kelapa klentik, minyak VCO, minyak zaitun, $\mathrm{KOH}$ (Bratachem), CMC (Bratachem), SLS (Bratachem), gliserin (Bratachem), Asam stearat (Bratachem), EDTA Na (Bratachem).

\section{Formula sabun mandi cair}

Formulasi sediaan sabun mandi cair dapat dilihat dalam tabel I yang dimodifikasi dari penelitian (kasenda et al, 2016).

\begin{tabular}{cccc}
\hline Bahan & \multicolumn{3}{c}{ Formula } \\
\hline Minyak kelapa & $10 \mathrm{ml}$ & $\mathbf{2}$ & $\mathbf{3}$ \\
Minyak VCO & - & $10 \mathrm{ml}$ & - \\
Minyak Zaitun & - & - & $10 \mathrm{ml}$ \\
KOH & $15 \mathrm{ml}$ & $15 \mathrm{ml}$ & $15 \mathrm{ml}$ \\
SLS & $2 \mathrm{~g}$ & $2 \mathrm{~g}$ & $2 \mathrm{~g}$ \\
Cocoamide DEA & $10 \mathrm{ml}$ & $10 \mathrm{ml}$ & $10 \mathrm{ml}$ \\
Gliserin & $25 \mathrm{ml}$ & $25 \mathrm{ml}$ & $25 \mathrm{ml}$ \\
Asam sitrat & $10 \mathrm{ml}$ & $10 \mathrm{ml}$ & $10 \mathrm{ml}$ \\
Na-EDTA & $1 \mathrm{~g}$ & $1 \mathrm{~g}$ & $\mathrm{Ig}$ \\
Aquades & Ad $100 \mathrm{ml}$ & Ad $100 \mathrm{ml}$ & Ad $100 \mathrm{ml}$ \\
\hline
\end{tabular}

Keterangan:

Formula I: menggunakan minyak kelapa Formula 2: menggunakan minyak VCO Formula 3: menggunakan minyak zaitun

\section{Evaluasi Sifat Fisik sabun Mandi Cair}

I. Uji karakteristik minyak

2. Uji Organoleptik

3. $\mathrm{Uji} \mathrm{pH}$

4. Uji Stabilitas Fisik

5. Uji Angka Lempeng Total

6. Uji Bobot Jenis

7. Uji Viskositas

\section{HASIL DAN PEMBAHASAN}

\section{Uji Karakteristik Minyak}

Uji ketidakjenuhan minyak Kelapa, VCO dan Zaitun

Uji ini dilakukan untuk mengetahui sifat ketidakjenuhan minyak. Hasil uji ketidakjenuhan minyak disajikan dalam tabel I.

Tabel I. Ketidakjenuhan Minyak

\begin{tabular}{cc}
\hline Jenis minyak & Larutan Brom \\
Kelapa & 49 tetes \\
VCO & 36 tetes \\
Zaitun & 98 tetes \\
\hline
\end{tabular}

Larutan bromin yang berwarna merah dapat dijadikan indikator terhadap senyawa lemak jenuh atau tidak karena bromin mampu bereaksi dengan ikatan rangkap pada lemak dengan cara memutus ikatan rangkap tersebut. Dari hasil pengujian diketahui bahwa minyak kelapa, VCO dan zaitun merupakan asam lemak tidak 
jenuh, karena saat ditetesi 2- 5 tetes brom, minyak belum berubah warna atau warna bromin hilang. Sementara setelah minyak kelapa ditetesi larutan brom sebanyak 49 tetes, minyak VCO ditetesi brom 36 tetes, dan minyak Zaitun ditetesi 98 brom barulah warna brom itu tetap ada atau tidak hilang, warna minyak menjadi merah. Semakin banyak larutan brom yang dibutuhkan maka semakin tinggi kadar asam lemak tak jenuh dari minyak tersebut. Dari banyaknya tetesan brom yang dibutuhkan untuk menetesi minyak agar warna brom tidak hilang maka minyak yang memiliki kadar asam lemak tak jenuh paling tinggi yaitu minyak zaitun dan yang terendah adalah minyak VCO.

\section{Uji Bobot Jenis Minyak}

Hasil uji bobot jenis minyak disajikan dalam tabel II.

Tabel II. Bobot Jenis Minyak

\begin{tabular}{ccc}
\hline Jenis minyak & $\begin{array}{c}\text { Bobot jenis } \\
(\mathbf{g} / \mathbf{m L})\end{array}$ & Standar $(\mathbf{g} / \mathbf{m L})$ \\
\hline Kelapa & 0,955 & $0,903-0,920$ \\
VCO & 0,956 & $0,940-0,950$ \\
Zaitun & 0,962 & $0,910-0,915$ \\
\hline
\end{tabular}

Standar bobot jenis minyak disebutkan dalam Farmakope Indonesia edisi III. Dari hasil uji bobot jenis diperoleh hasil yang mendekati standar. Bobot jenis minyak zaitun lebih tinggi dibandingkan dengan minyak kelapa dan VCO. Hal ini terjadi karena minyak zaitun memiliki kandungan asam lemak tak jenuh paling tinggi diantara minyak kelapa dan VCO. Berat jenis minyak naik dengan naiknya derajat ketidakjenuhan minyak (Handajani et al, 2010). Terurainya lemak tak jenuh ini dapat menyebabkan terbentuknya produk sekunder bermolekul besar yang akan meningkatkan kerapatan struktur minyak. Bobot jenis yang tidak sesuai dengan standar berarti minyak tersebut tidak murni (Farida dan Siregar, 2006).

\section{Uji organoleptis}

Uji organoleptis dilakukan secara visual pada sediaan. Hasil uji organoleptis disajikan dalam tabel III.
Tabel III. Organoleptis Sediaan Sabun Mandi Cair

\begin{tabular}{|c|c|c|c|}
\hline Sediaan & Bentuk & Warna & Bau \\
\hline $\begin{array}{c}\text { Sabun cair } \\
\text { kelapa }\end{array}$ & $\begin{array}{l}\text { Cair, mudah } \\
\text { mengalir }\end{array}$ & Putih & $\begin{array}{l}\text { Tidak } \\
\text { berbau }\end{array}$ \\
\hline $\begin{array}{l}\text { Sabun cair } \\
\text { VCO }\end{array}$ & $\begin{array}{l}\text { Cair, mudah } \\
\text { mengalir }\end{array}$ & Putih & $\begin{array}{l}\text { Tidak } \\
\text { berbau }\end{array}$ \\
\hline $\begin{array}{c}\text { Sabun cair } \\
\text { Zaitun }\end{array}$ & $\begin{array}{l}\text { Cair, mudah } \\
\text { mengalir }\end{array}$ & Putih & $\begin{array}{l}\text { Tidak } \\
\text { berbau }\end{array}$ \\
\hline
\end{tabular}

\section{Uji pH}

Uji $\mathrm{pH}$ merupakan parameter penting untuk menentukan derajad keasaman pada suatu sediaan. Hasil pengujian $\mathrm{pH}$ pada sabun mandi cair kelapa, VCO dan zaitun berada pada kisaran $\mathrm{pH}$ 6-7, hasil ini sesuai dengan persyaratan sabun mandi cair yang berkisar 6-8 (SNI, 1996). Nilai pH sabun yang terlalu rendah dapat menyebabkan peningkatan daya absorbsi sabun pada kulit sehingga dapat menyebabkan iritasi pada kulit, sedangkan nilai $\mathrm{pH}$ yang terlalu tinggi juga dapat menyebabkan iritasi pada kulit (Untari dan Robiyanto, 2018). Hasil uji $\mathrm{pH}$ disajikan dalam tabel IV dan V.

Tabel IV. Perbandingan rerata $\mathrm{pH}$ antar kelompok

\begin{tabular}{ccc}
\hline Jenis minyak & pH & $\mathbf{P}$ \\
\hline Kelapa & $6,62 \pm 0,02$ & \\
VCO & $6,94 \pm 0,04$ & 0,000 \\
Zaitun & $6,49 \pm 0,03$ & \\
\hline
\end{tabular}

Dalam tabel $\mathrm{V}$ disebutkan bahwa $\mathrm{pH}$ sabun cair zaitun memiliki $\mathrm{pH}$ paling asam. Hal ini disebabkan karena minyak zaitun memiliki asam lemak tak jenuh paling tinggi yang mudah teroksidasi. Proses oksidasi ini menyebabkan minyak menjadi asam, sehingga $\mathrm{pH}$ menjadi lebih asam dibandingkan sabun kelapa dan VCO (Kadir et al, 20I5).

Hasil uji statistik nilai $\mathrm{pH}$ dengan uji normalitas menggunakan Kolmogrov Smirnov didapatkan bahwa data terdistribusi normal dengan nilai signifkan $(p<0,05)$. Kemudian dilakukan uji ANOVA didapatkan hasil signifikan pada ketiga kelompok $(p<0,05)$.

Tabel V. Perbandingan rerata $\mathrm{pH}$ antar kelompok setelah intervensi

\begin{tabular}{cccc}
\hline Jenis minyak & $\begin{array}{c}\text { Mean } \\
\mathbf{p H}\end{array}$ & $\begin{array}{c}95 \% \mathrm{Cl} \\
\text { Lower }\end{array}$ & Upper \\
\hline
\end{tabular}




\begin{tabular}{ccccc}
\hline Kelapa vs VCO & $-0,32 \pm$ & $-0,38$ & $-0,26$ & 0,000 \\
& 0,02 & & & \\
Kelapa vs & $0,14 \pm$ & 0,08 & 0,20 & 0,002 \\
Zaitun & 0,02 & & & \\
VCO vs Zaitun & $0,46 \pm$ & 0,40 & 0,52 & 0,000 \\
& 0,20 & & \\
\hline
\end{tabular}

Untuk melihat adanya perbedaan kelompok sabun, dilanjutkan dengan uji LSD. Hasil uji LSD menunjukkan ada perbedaan signifikan antaran ketiga kelompok formula $(p<0,05)$.

\section{Uji stabilitas fisik}

Uji stabilitas fisik pada sediaan sabun mandi cair dilakukan dengan alat sentrifugator Ohaus dengan kecepatan 10.000 rpm. Pengujian ini dilakukan untuk melihat ada tidaknya pemisahan fase sabun cair, agar dapat memperkirakan waktu penyimpanan pada suatu sediaan. Uji stabilitas menggunakan metode mechanical test, sampel sabun cair disentrifugasi dengan kecepatan putaran 10.000 rpm selama 30 menit, karena hasilnya ekuivalen dengan efek gravitasi selama I tahun. Kemudian diamati secara visual (Sinaga et al, 2007). Hasil pengujian dapat dilihat pada gambar I.
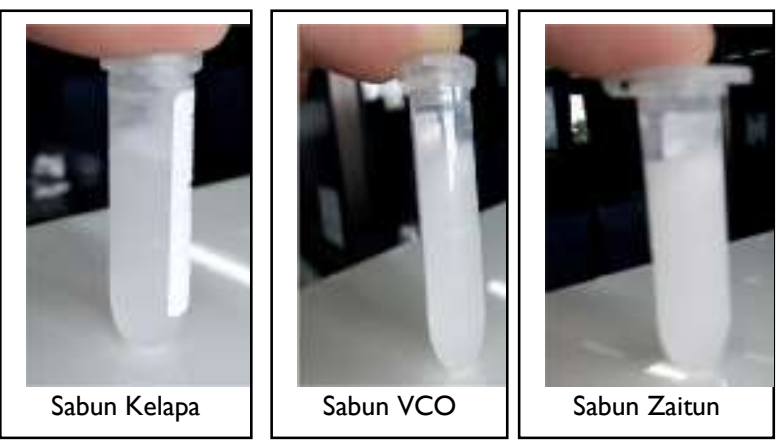

Gambar I. Hasil Uji Stabilitas Sabun Mandi Cair Dari ketiga formula tidak terdapat fase yang terpisah, jadi bisa dikatakan sediaan sabun mandi cair kelapa, VCO dan zaitun stabil dalam penyimpanan selama I tahun.

\section{Uji angka lempeng total}

Teknik yang digunakan dalam pengujian ini adalah teknik cawan tuang (pour plate). Jumlah ALT yaitu
IxI05.(SNI, 1996). Hasil uji ALT disajikan dalam tabel VI.

Tabel VI. Hasil Uji Angka Lempeng Total

\begin{tabular}{lcl}
\hline \multicolumn{1}{c}{ Jenis minyak } & ALT & SNI \\
\hline Sabun mandi cair Kelapa & $2,0 \times 10^{1}$ & \\
Sabun mandi cair VCO & $1,5 \times 10^{1}$ & $<1 \times 10^{5}$ \\
Sabun mandi cair Zaitun & $1,0 \times 10^{1}$ & \\
\hline
\end{tabular}

Hasil uji menunjukkan bahwa Angka Lempeng Total dari semua sediaan sabun mandi cair $<|x| 05$. Artinya sabun yang dihasilkan aman digunakan karena mengandung bakteri yang relatif kecil dan memenuhi standar.

\section{Uji bobot jenis}

Bobot jenis adalah rasio bobot suatu zat terhadap bobot zat baku yang volumenya sama pada suhu yang sama dan dinyatakan dalam desimal. Hasil uji bobot jenis sediaan sabun mandi cair disajikan dalam tabel VII.

Tabel VII. Hasil Uji Bobot Jenis Sabun mandi Cair

\begin{tabular}{ccc}
\hline Jenis minyak & $\begin{array}{c}\text { Bobot jenis } \\
(\mathbf{g} / \mathbf{m L})\end{array}$ & SNI (g/mL) \\
\hline Sabun mandi cair Kelapa & $\mathrm{I}, 0425$ & \\
Sabun mandi cair VCO & $\mathrm{I}, 0427$ & $\mathrm{I}, 0 \mathrm{I}-\mathrm{I}, \mathrm{I0}$ \\
Sabun mandi cair Zaitun & $\mathrm{I}, 05 \mathrm{II}$ & \\
\hline
\end{tabular}

Dari hasil penelitian ini sabun mandi cair yang dihasilkan semuanya lebih dari I,00 dan kurang dari I,I0 yang artinya dari ketiga formula tersebut semuanya telah memenuhi standar bobot jenis sesuai SNI. Bobot jenis dari ketiga formula sabun cair bisa lebih tinggi daripada bobot jenis air karena dalam formula sabun mandi cair selain mengandung minyak juga mengandung bahan tambahan lainnya. Dalam uji ini diperoleh bobot jenis sabun cair zaitun paling tinggi, hal ini karena bobot jenis minyak zaitun lebih tinggi dibanding minyak kelapa dan VCO. Setiap bahan baku yang ditambahkan dalam formulasi sabun mandi cair sangat menentukan bobot jenis sabun yang dihasilkan (Basito et al, 2018). Nilai bobot jenis dari ketiga formula sabun cair yang dihasilkan sudah memenuhi kriteria SNI 06-4085-1996 yaitu bobot jenis berkisar dari I,0I - I,I0. Bobot jenis 
yang memenuhi standar membuat sediaan sabun cair menjadi stabil dalam penyimpanan.

\section{Uji viskositas}

Tujuan dilakukan uji viskositas pada sediaan untuk mengetahui sifat laju alir dan tingkat kekentalan pada sabun mandi cair. Penggunaan spindel cup and bob mampu bekerja pada sediaan yang memiliki viskositas yang rendah dan suspensi seluler dan memiliki luas permukaan yang besar sehingga memberikan sensitivitas yang tinggi dan menghasilkan data yang baik pada shear rate dan viskositas yang rendah.

Tabel VIII. Perbandingan Rerata Uji Viskositas antar kelompok

\begin{tabular}{ccc}
\hline & Viscositas (cps) & P \\
\hline Jenis minyak & $557,67 \pm 49,34$ & \\
Kelapa & $685,67 \pm 75,53$ & 0,003 \\
Zaitun & $419,67 \pm 14,74$ & \\
\hline
\end{tabular}

Tabel IX. Perbandingan rerata uji viskositas antar kelompok setelah intervensi

\begin{tabular}{ccccc}
\hline Jenis minyak & $\begin{array}{c}\text { Mean } \\
\text { viscositas }\end{array}$ & \multicolumn{2}{c}{$95 \% \mathbf{C l}$} & P \\
& & Lower & Upper & \\
\hline Kelapa vs VCO & $-128 \pm 43$ & $-233,44$ & $-22,56$ & 0,025 \\
Kelapa vs Zaitun & $138 \pm 43$ & 32,56 & 243,44 & 0,019 \\
VCO vs Zaitun & $266 \pm 43$ & 160,56 & 371,44 & 0,001 \\
\hline
\end{tabular}

Dari tabel di atas diketahui bahwa viskositas untuk masing-masing sabun sudah memenuhi standar yang ditetapkan yaitu antara 400 - 4000cps. Semakin tinggi viskositas maka akan semakin tinggi stabilitasnya, karena pergerakan partikel cenderung lebih sulit dan lebih kental. Dalam pengujian ini formula sabun mandi cair VCO mempunyai viskositas yang paling tinggi yakni 686cps. Jadi bisa dikatakan sabun mandi cair VCO tingkat stabilitasnya lebih baik dibanding formula sabun mandi cair kelapa dan Zaitun. Semakin banyak jumlah asam lemak jenuh dalam sabun, maka sabun akan menjadi kental. Minyak VCO memiliki kandungan asam lemak jenuh paling tinggi diantara minyak Zaitun dan kelapa, hal ini menyebabkan sabun yang dihasilkan oleh minyak VCO memiliki kekentalan yang paling tinggi (Oktari et al, 20l7).
Hasil uji statistik nilai viskositas dengan uji normalitas menggunakan Kolmogrov Smirnov didapatkan bahwa data terdistribusi normal dengan nilai signifkan $(p<0,05)$. Kemudian dilakukan uji ANOVA didapatkan hasil signifikan pada ketiga kelompok $(p<0,05)$.

\section{KESIMPULAN}

Sabun yang dihasilkan mempunyai $\mathrm{pH}$, bobot jenis, angka lempeng total dan viskositas yang memenuhi standar SNI sabun mandi cair. Minyak yang paling optimal dalam menghasilkan sabun mandi cair yang memenuhi persyaratan adalah minyak zaitun.

\section{UCAPAN TERIMA KASIH}

Terimakasih kami ucapkan kepada Universitas Ahmad Dahlan, Laboratorium Universitas Ahmad Dahlan, Dosen Pembimbing dan seluruh laboran yang sudah membantu dalam penelitian ini.

\section{REFERENSI}

I. Kasenda, J. C., Yamlean, P. V. Y. dan Lolo, W. A. 2016. Formulasi dan Pengujian Aktivitas Antibakteri Sabun Cair Ekstrak Etanol Daun Ekor Kucing (Acalypha hispida Burm. F) Terhadap Pertumbuhan Bakteri Staphylococcus aureus, PHARMACON Jurnal IImiah Farmasi, 5(3), pp. 40-47.

2. Oktari, W. dan W. 2017. Pengaruh Jenis Minyak Dan Konsentrasi Larutan Alginat Terhadap Karakteristik Sabun Cair Cuci Tangan, Jurnal Farmasi, 5(2), pp. 4757.

3. Tiffani, F. et al.. 20I5. Efek Pemberian Minyak Zaitun (Olea europa) Terhadap Penyembuhan Luka Insisi Mencit jantan Galur Swiss Webster, Publication Universitas kristen Maranatha.

4. Handajani, S., Manuhara, G. dan Anandito, R. 2010. Pengaruh Suhu Ekstraksi Terhadap Karakteristik Fisik, Kimia Dan Sensoris Minyak Wijen (Sesamum Indicum L.), Agritech: Jurnal Fakultas Teknologi Pertanian UGM, 30(2), Pp. 116-122. doi: 10.22 |46/agritech.9682.

5. Farida dan Siregar. 2006. Pengaruh Pemanasan Berulang Terhadap sifat Fisikokimia dan Kandungan asam palmitat pada minyak goreng,. Jurnal IImu Kefarmasian Indonesia, 4(2), pp. 83-9I. 
6. SNI .1996. Sabun Mandi Cair, 06-4085-1996.

7. Untari, E. K. dan Robiyanto, R. 2018. Uji Fisikokimia dan Uji Iritasi Sabun Antiseptik Kulit Daun Aloe vera (L.) Burm. f, Jurnal Jamu Indonesia, 3(2), pp. 55-6I. doi: $10.29244 / j j i . v 3 i 2.54$.

8. Kadir et al. 2015. Penggunaan Kayu Manis (Cinnamomum burmani) Untuk Mengatasi Ketengikan Pada Minyak kelapa Secara Tradisional, Jurnal Photon, 5(2).

9. Sinaga, A. A., Luliana, S. dan Fahrurroji, A. 2015. Losio Antioksidan Buah Naga Merah (Hylocereus polyrhizus Britton and Rose), Pharmaceutical Sciences and Research, 2(I), hal. II-20. doi: 10.7454/psr.v2il.3333. 